Bot. Mag. Tokyo 77: 59-65 (February 26, 1964)

\title{
邦産キク亜科植物の細胞学的研究 XVI.
}

\section{サワギク族における核型分析}

\author{
荒野 久 雄*
}

Hisao Arano*: Cytological Studies in Subfamily Carduoideae

(Compositae) of Japan XVI.

The Karyotype Analysis in Tribe Senecioneae

1963 年 12 月 11 日受付

すでにサワギク族 (Senecioneae) に含まれる $L i$ gularia 属の 3 種, Senecio 属の 5 種特よび Farfugium 属の 2 種について, その核型ならびに若干 の系統的考察を報告した卢が，今回は Ligularia 属 の 3 種特よび Senecio 属の 2 種について核型分析 を行なったので，その結果を報告する。

\section{材料および方法}

研究材料はすべて 1959 年 6 月より 1963 年 7 月 の間に特いて，主として中部山地，東北，北海道 の海岸特よび高山で採集したものである。特に $L$. angusta は神奈川県真鶴岬で採焦し, 開花期は他の 同属のものより早く 5 月中で， 6 月には地上部は祜 死し, 根の生長はと末ってし季い, 移植を特にき
らい, 枯れることが多いので根端の採取に困難があ った。 末た S. pseudo-arnica は北海道襟裳岬産の ものである. 材料植物についての詳細は第 1 表に記 したと呿りである。

研究方法は前報1) と同様である。

L. angusta は根の生長速度が遅く, 分裂の時期 も早朝とか夕刻とかにかたよって特り，分裂像をさ がすのに多少てまでった。

\section{観 察 結 果}

1. L. augusta (ヤマタバコ), $2 \mathrm{n}=58$, 真鶴岬 産(神奈川県), Figs. 1, 6.

本種の体細胞染色体数については $2 \mathrm{n}=58$ が根端 細胞の分裂に特いて観察された。本種は花部の特徴

Table 1. Chromosome numbers in Ligularia and Senecio.

\begin{tabular}{|c|c|c|c|}
\hline \multirow{3}{*}{ Species } & \multicolumn{2}{|c|}{ Chromosome number } & \multirow{3}{*}{ Localities } \\
\hline & \multicolumn{2}{|c|}{$\begin{array}{ll}\begin{array}{l}\text { Previous } \\
\text { records }\end{array} & \begin{array}{l}\text { Present } \\
\text { records }\end{array}\end{array}$} & \\
\hline & $\mathrm{n} \quad 2 \mathrm{n}$ & $2 n$ & \\
\hline S. pseudo-arnica & 2 & 40 & Erimomisaki in Hokkaido \\
\hline S. nemorensis & $\begin{array}{l}20 \\
\text { (Matsuura and }\end{array}$ & $\begin{array}{c}40 \\
\text { Suto) }\end{array}$ & Mt. Shiraiwa in Saitama Pref. \\
\hline L. angusta & & 58 & Manazuru in Kanagawa Pref. \\
\hline L. fischerii & & 60 & Mt. Norikura in Nagano Pref. \\
\hline L. hodgsonii & $\begin{array}{c}58 \\
(\text { Afzelius) }\end{array}$ & 58 & Tazawa-Ikubo in Akita Pref. \\
\hline
\end{tabular}

* 昭和薬科大学生物学研究室 Biological Institute, Showa Pharmaceutical College, Tokyo, Japan. 
によれば Ligularia 属に含まれることが理解され るがまだ花穂のあらわれない頃には同属の他種と 外部形態的に著しく相違している。特に巨大な根生 葉的なさじ形の全縁葉と葉面に厚くろう被層が発達 し，早期に開花するなど著しい差がみられるもので ある。

染色体の大きさは最大 $6 \mu$ から最小 $4 \mu$ の範囲 で，一般に大型であり，ほぼ Ligularia 属の他種 に共通的な大きさである。

染色体組は染色体の大きさと形態によって 3 群に 大別することが適当である。大型染色体群は 4 対の 中部㹨窄型特よび 3 対の次中部狭窄型染色体を除け ばすべて次端部狭窄型のものである，中位の大きさ 以下の染色体群には 1 対ずつの次端部狭窄型特よび 端部側に近く狭窄をもつ次端部狭窄型染色体が含末 れるが，残りは 6 対の次中部狭窄型染色体と 12 対 の中部狭窄型染色体である.

核型は概して不対称核型であり，次の式によって 示すことができる.

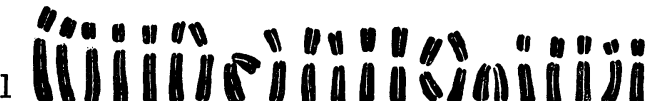

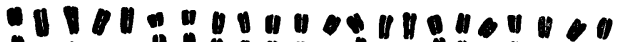

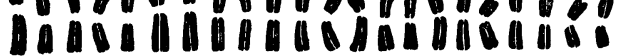

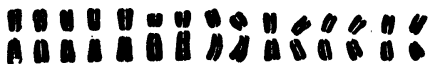

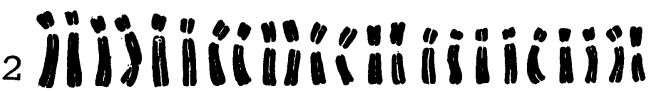

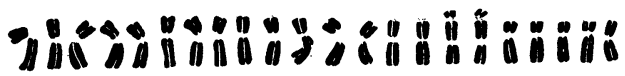

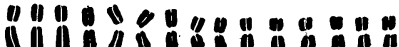

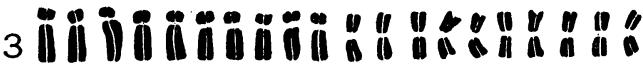

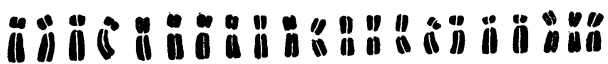

\section{8}

Figs. 1-3. Schematic representations of the karyotype of Ligularia. 1, L. angusta, $2 \mathrm{n}=58 ; 2, L$. fischerii, $2 \mathrm{n}=60 ; 3, L$. hodgsonii, $2 \mathrm{n}=58$.

$$
\begin{aligned}
\mathrm{K}=58= & 6 \mathrm{~A}_{1} \mathrm{st}+6 \mathrm{~A}_{1} \mathrm{sm}+4 \mathrm{~A}_{1} \mathrm{~m}+6 \mathrm{~A}_{2} \mathrm{st}+4 \mathrm{~A}_{2} \mathrm{~m} \\
& +2 \mathrm{Bst} \rightarrow \mathrm{t}+6 \mathrm{Bsm}+2 \mathrm{Bm}+4 \mathrm{C}_{1} \mathrm{sm}+8 \mathrm{C}_{1} \mathrm{~m} \\
& +2 \mathrm{C}_{2} \mathrm{st}+2 \mathrm{C}_{2} \mathrm{sm}+6 \mathrm{C}_{2} \mathrm{~m}
\end{aligned}
$$

2. L. fischerii (オタカラコウ), $2 \mathrm{n}=60$, 乘 鞍岳産 (長野県), Figs. 2, 7 .

本種の体細胞染色体数は根端に 抽いて $2 \mathrm{n}=60$ が観察された，染色体は一般に大きく，最大 $6 \mu$ より最小 $4.3 \mu$ の範囲で，個々の染色体の間の大 きさの差はやや著しい。

染色体組は前種 $L$. angusta と同様に，染色体 の大きさと㹨窄の位置にしたがって 3 群に分ける ことがでさる， 7 対の大型染色体群は 1 対の中部 狭窄型染色体のほか子す心゙て端部側に近く狭窄を もつ次端部㹨窄型の 4 対とそれに近い狭窄をるつ 染色体である。次に中型の染色体群は 1 対の中部狭 窄型の染色体と 8 対の次中部狭窄型染色体以外は 4 対の次端部㹨窄型染色体である。小型の染色体群は 2 対の次端部狭窄型以外は中部狭窄型あるいはこれ に近い次中部狭窄型染色体である，さらに中位の大 きさの 1 対の第 2 次狭窄型染色体が存在する. 核型 は一般に不対称核型であり，次の上うにあらわすこ とができる。

$$
\begin{aligned}
\mathrm{K}=60= & 8 \mathrm{~A}_{1} \mathrm{st}+4 \mathrm{Asm}+2 \mathrm{Am}+8 \mathrm{~B}_{1} \mathrm{st}+16 \mathrm{~B}_{1} \mathrm{sm} \\
& +2 \mathrm{csB}_{1} \mathrm{~m}+4 \mathrm{~B}_{2} \mathrm{st}+4 \mathrm{~B}_{2} \mathrm{sm}+4 \mathrm{~B}_{2} \mathrm{~m}+8 \mathrm{Cm}
\end{aligned}
$$

3. L. hodgsonii (トウゲブキ), $2 \mathrm{n}=58$, 田沢 湖生保産 (秋田県), Figs. 3, 8.

本種の根端細胞の分裂に特いて $2 \mathrm{n}=58$ の体染色 体数がかぞ兄られた，染色体の大きさ概して大型 で最大 $6 \mu$ から最小 $4.2 \mu$ の䈖囲であり, 個々の染 色体の大きさの差はあまり著しくない。

染色体組は染色体の大きさと形態によって 3 群に 区分される. 17 刘の大型染色体群は 8 対の次端狭 窄型特よび 3 対の次中部㹨窄型染色体のほかは 6 対 の中部狭窄型染色休からなり，中位の大きさの群は 1 対の中部狭窄型特よび 2 対の端部側に近く㹨窄を b つ次端部㹨窄型染色体 (st $\rightarrow \mathrm{t}$ 㹨窄型染色体) 以 外はすべて次中部狭窄型染色体である。 3 対の最小 の小型染色体群はすべて次中部狭窄型のものであ る.

核型は不対称的であり，次式により示すことがで きる。

$$
\begin{aligned}
\mathrm{K}=58= & 6 \mathrm{~A}_{1} \mathrm{st}+4 \mathrm{~A}_{2} \mathrm{st}+10 \mathrm{~A}_{2} \mathrm{~m}+4 \mathrm{~A}_{3} \mathrm{st}+6 \mathrm{~A}_{3} \mathrm{sm} \\
& +4 \mathrm{~A}_{3} \mathrm{~m}+4 \mathrm{Bst} \rightarrow \mathrm{t}+10 \mathrm{Bsm}+2 \mathrm{Bm}
\end{aligned}
$$




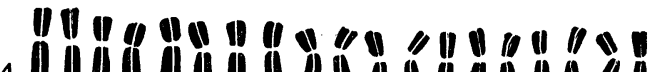

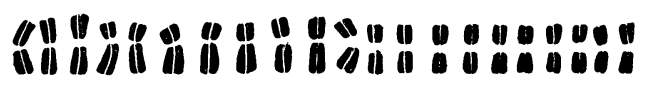

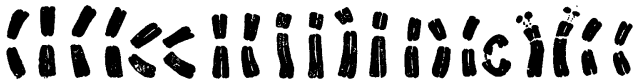

Figs. 4-5. Schematic representation of the karyotypes of Senecio. 4, S. nemorensis, $2 \mathrm{n}$ $=40 ; 5$, S. pseudo-arnica, $2 \mathrm{n}=40$.

$$
+4 \mathrm{Csm} \rightarrow \mathrm{st}+4 \mathrm{Csm} \rightarrow \mathrm{m}
$$

4. Senecio nemorensis (キオン), $2 \mathrm{n}=40$, 白 岩山産(埼玉県), Figs 4, 9.

本種については体細胞染色体 $2 \mathrm{n}=40$ がすでに松 浦と須藤2)によって報告されているが，筹者の観察 もこれと一致している。

個々の染色体の大きさの差はきわめて小さく, 最 大 $4 \mu$ から最小 $3 \mu$ の範团で概して大きい.

染色体組は染色体の大ささと形態とにより 3 群に 大別することができる，各群に属する 1 対ずつ特よ び小型群の 2 対の染色体が炊中部狭窄型であるほか は，すべて中部狭窄型あるいはこれに近いもののみ である. 次端部, または端部狭窄型のものは億めら れない.

したがって核型はきわめて高い対称型のもので, 前報告1)のS. cannabifolius の核型によくにてい て，両者はきわめて系統的に近縁であり，いずれも あまり進化しない核型をもつことが指摘される。核 型は次式によって示すことができる。

$$
\begin{aligned}
\mathrm{K}=40= & 2 \mathrm{Asm}+4 \mathrm{Asm} \rightarrow \mathrm{m}+4 \mathrm{Am}+2 \mathrm{Bsm}+12 \mathrm{Bm} \\
& +2 \mathrm{C}_{1} \mathrm{sm}+10 \mathrm{C}_{1} \mathrm{~m}+4 \mathrm{C}_{2} \mathrm{sm}
\end{aligned}
$$

5. S. pseudo-arnica (エゾオグルマ), $2 \mathrm{n}=40$, 襟裳岖産 (北海:道), Figs. 5, 10.

本種の体細胞染色体数は $2 \mathrm{n}=40$ が根端細胞の分 裂中期に扔いて認められた。花粉母細胞の分裂に特 いて 20 個の 2 価染色体の正常の行動が観察された. したがって本種は $b=10$ の同質四倍体と認めるこ とができる。
染色体の大きさは最大 $4.2 \mu$ より最小 $2 \mu$ の 範团であり，個々の染色体の長さの差は著しく ない.

染色体組は染色体の大きさと狭窄の位置にし たがって 3 群に区分される。特に大型の 2 対の 中部狭窄型染色体の存在が目だつが，中位の大 きさの 1 対の第二次㹨窄型染色体和よび 2 対の 次端部狭窄型染色体（st $\rightarrow \mathrm{t}$ 㹟窄型染色体で Senecio 属の多くの種にみられる）を除けば, 残りはすべて中部㹨窄型もしくはこれに近い次 中部狭窄型染色体 $(\mathrm{sm} \rightarrow \mathrm{m}$ 狭窄型) のみから なり，核型はきわわて高い対称的核型をもって いる.

核型は次式によってあらわすことができる。

$$
\mathrm{K}=40=4 \mathrm{~A}_{1} \mathrm{~m}+6 \mathrm{~A}_{2} \mathrm{sm} \rightarrow \mathrm{m}+18 \mathrm{~A}_{2} \mathrm{~m}+2 \mathrm{csA}_{2} \mathrm{st}
$$$$
+4 \mathrm{Bst} \rightarrow \mathrm{t}+2 \mathrm{C}_{1} \mathrm{sm} \rightarrow \mathrm{m}+2 \mathrm{C}_{1} \mathrm{~m}+2 \mathrm{C}_{2} \mathrm{~m}
$$

\section{考察}

筆者はすでに Senecioneae（サワギク族）の Senecio 属特よびその近接属種の間には一連の核型進 化の系列が存在することを報告した ${ }^{1)}$ 。すなわち, 狭窄の位䚑がいずれも中部またはとれに近い対称型 の核型 (S. cannabifolius) からやや狭窄の末端化 の始玉りかけた柽度の不刘称核型 (S. pierotii, S. flammeus ssp. glabrifolius) を経て, さらに狭窄 が末端化の著しい高度の不刘称核型（Erechtites hieracifolia) への変化がみられ，さらに進んで核 型が構造的に複雑化し，2 個の付随体をもつ特異 形態の第三次㹨窄型染色体の種がみいだされてい る3).このように染色体の大きさに稀いてもほとん ぞ著しい差のないものから备染兒体の大きさに差が 生じて大小に分かれたものなどにいたるサワギク族 の進化の段階の種々の断面を核型の上に明らかに認 めることができる(第 2 表).

Senecio 属中, 最子低次の $2 \mathrm{n}=20$ の. S. scandens は基本数 $\mathrm{b}=10$ の二倍体で核型はやや不対称 型であり，分類的には Synotis 節に曆している4,5).

隣接の Nemosenecio 節に属する S.nikoensis は S. cannabifolius と同様に $2 \mathrm{n}=40$ であるが，核学 的には 2 対の端部側に近く狭窄をもつ次端部狭窄型 染色体 (st $\rightarrow \mathrm{t}$ 㹟窄型染色体) の存在によってやや 不対称核型により区別される。また同節の S. nemorensis も同一染色体数をもつが次端部狭窄型染 
Table 2. Karyotypic constitutions in Senecio, Ligularia, Emilia and Erechtites.

\begin{tabular}{|c|c|c|c|c|c|c|c|}
\hline \multirow{2}{*}{ Species } & \multicolumn{7}{|c|}{ Chromosomest } \\
\hline & $c t$ & $\mathrm{cs}$, & st, & $\mathrm{sm}$, & $\mathrm{m}$ & Total & Size $(\mu)$ \\
\hline S. pierotii & & & 4 & 8 & 36 & 48 & $\begin{array}{lll}4 & -2\end{array}$ \\
\hline S. flammeus ssp. glabrifolius & & & 10 & 10 & 26 & 46 & $4-2$ \\
\hline S. nikoensis & & & 4 & 4 & 32 & 40 & $3.2-2$ \\
\hline S. scandens & & & 2 & 6 & 12 & 20 & $\begin{array}{lll}3 & -2\end{array}$ \\
\hline S. cannabifolius & & & & 8 & 32 & 40 & $\begin{array}{lll}4 & -3\end{array}$ \\
\hline S. nemorensis & & & & 14 & 26 & 40 & $\begin{array}{ll}4 & -3\end{array}$ \\
\hline S. pseudo-arnica & & 2 & 4 & 8 & 26 & 40 & $4.2-2$ \\
\hline L. dentata & & & 10 & 32 & 18 & 60 & $6-4$ \\
\hline L. stenocephala & & & 14 & 28 & 18 & 60 & $6.5-4.2$ \\
\hline L. kaialpina & & & 16 & 32 & 10 & 58 & $6-4$ \\
\hline L. angusta & & & 14 & 18 & 26 & 58 & $\begin{array}{ll}6 & -4\end{array}$ \\
\hline L. fischerii & & 2 & 20 & 26 & 12 & 60 & $\begin{array}{lll}6 & -4.3\end{array}$ \\
\hline L. hodgsonii & & & 20 & 22 & 16 & 58 & $6-4.2$ \\
\hline$F \cdot$ japonicum & & 2 & 38 & 20 & & 60 & $\begin{array}{lll}5 & -3\end{array}$ \\
\hline$F$. hiberniflorum & & 2 & 44 & 14 & & 60 & $\begin{array}{lll}5 & -3.2\end{array}$ \\
\hline E. sonchifolia & 2 & & 12 & 6 & & 20 & $\begin{array}{lll}8 & -3\end{array}$ \\
\hline Erechtites hieracifolia & & & 32 & 8 & & 40 & $\begin{array}{ll}6 & -2.3\end{array}$ \\
\hline
\end{tabular}

$\dagger c t$, tertiary constriction; cs, secondary constriction; st, subterminal constriction; $\mathrm{sm}$, submedian constriction; $\mathrm{m}$, median constriction.

色体を欠き，核型は著しく刘称的核型である，S. cannabifolius の核型に類似して両者は系統的に密 接な関係にあることが核型を通して認められる。

次に前述の S. nikoensis の核型に類似要素をも ち, 2 刘の次端部狭窄型染色体 ( $\mathrm{st} \rightarrow \mathrm{t}$ 狭窄型)をもつ が全体的にはやや対称的の核型をるつ S. pierotii 特よび S. flammeus ssp. glabrifolius は異なる Tephroseris 節に所属している4). これらの種は $2 \mathrm{n}=48,46$ をそれぞれもっている．これらの種の るつ基本数は第二次的に $\mathrm{b}=5$ あるいは $\mathrm{b}=10$ か ら誘導されたものと考兄られる。

さらに今回核型分析を行なったS.pseudo-arnica は第二次狭窄型染色体を子ち, かつ特有的な $S$. pierotii に含まれるような 2 対の次端部狭窄型染色 体 (くわしくは $\mathrm{st} \rightarrow \mathrm{t}$ 狭窄型染色体) の存在を認め ることができる. 核型は比較的対称型に近いもの で Tephroseris 節の種の核型によく似ているが, 基本数の相違によって明らかに区別されねばならな w.
この種の核型は 2 対の次端部狭窄型染色体の存在 を除けば，きわめて高度の対称核型を示し，Nemosenecio 節に核学的に包含される。また核型的には 類似性の高いことからは Tephroseris 節に所属さ れるべきであるが，体細胞染色体数の相違によって S. pseudo-arnica の核型は核学的に特異的存在と みなすことができよう。北村 ${ }^{4}$ は分類学的に Crociseris 節として特設させているが，核型からもとの 根拠を与觉ることができると考㝋られる。

次に Senesio 属ならびに Senecioneae（サワギ ク族）の染色体数特よびその基本数については，ま ず Afzelius'), Darlington ${ }^{8)}$, Beaman, De Jong, Stoutamire ${ }^{9)}$ は最近 Senecio 属に执ける最子共通 な染色体数は $\mathrm{n}=20$ であり，サワギク族またサワ ギク属の基本数は $\mathrm{b}=5$ と考㝋ている. Ornduff 特よび Peter6) らによれば $\mathrm{b}=5$ はサワギク族の 3 種の一年生のものにのみ知られている (S. discifolius, Emilia sagittata, E. sonchifolia の 3 種). この Emilia 属はしばしば Senecio 属にいれられ 

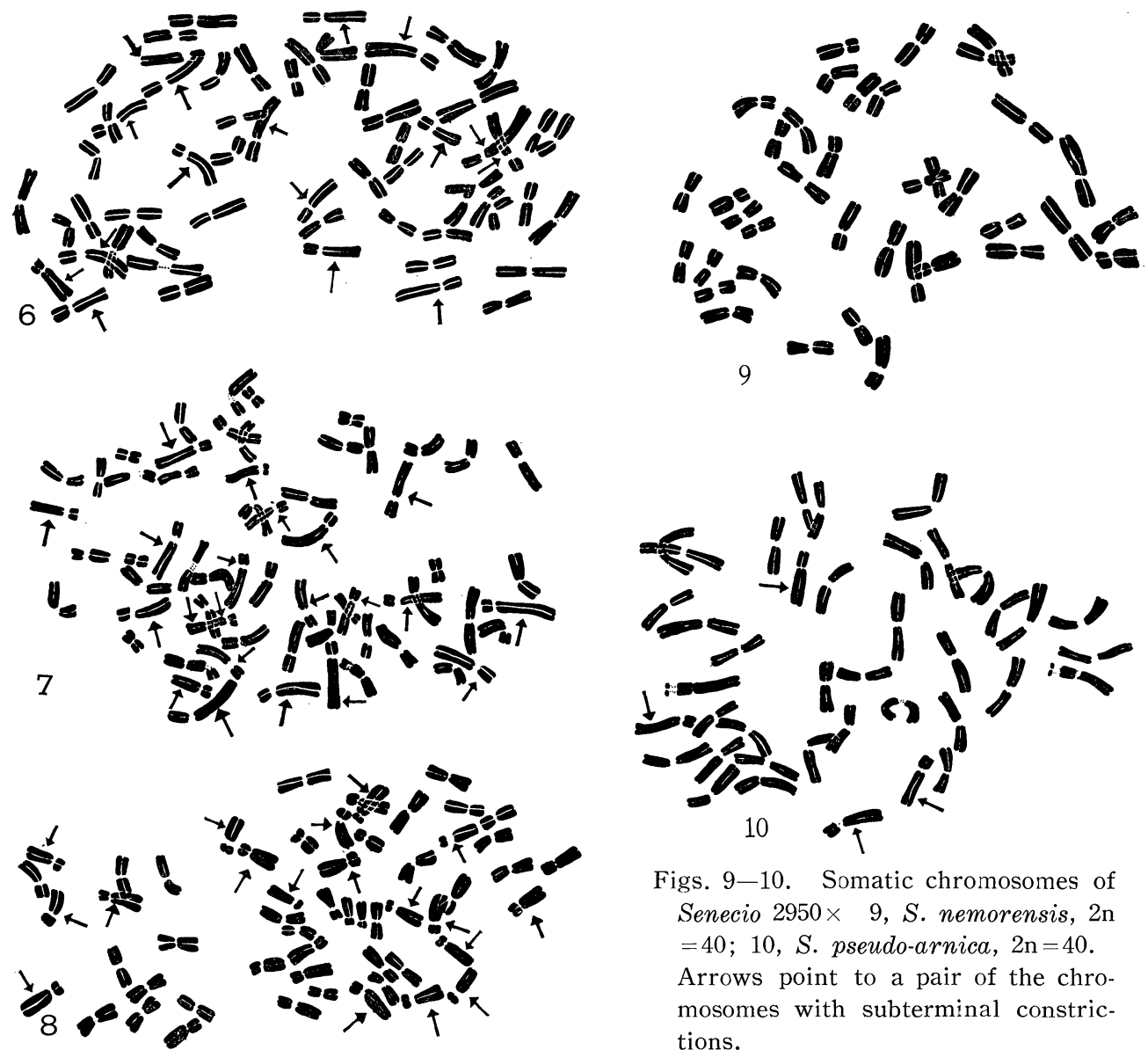

Figs. 6-8. Schematic chromosomes of Ligularia. $2650 \times 6$, L. angusta, $2 \mathrm{n}=58 ; 7$, L. fischerii, $2 \mathrm{n}=60 ; 8$, L. hodgsonii, $2 n=58$. Arrows point to a pair of the chromosomes with subterminal constriction.

ることがある。これは筆者の核学的知見からは不適 当である. しかし，もしこの $b=5$ がこのサワギク 族, サワギク属の基本数であるならば 10 の倍数性的 系列だけでなく，5の倍数的関係の $15,25,35$ など があらわれてもよいわけである。乙かし実際には注 とんど知られていない. したがってこの族の基本数

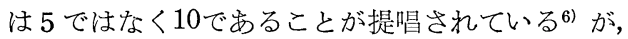
筆者の考察もこれに一致するものである.

これらを総合的に考穴るとき，Senecio 属には 10 （または 5) を正常の基本数とする比較的対称的核 型字子つ直系的な倍数系列群 $(\mathrm{n}=5,10,20,30,40$

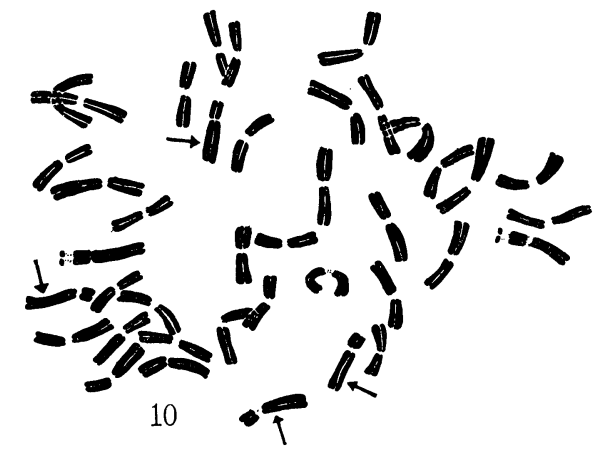

Figs. 9-10. Somatic chromosomes of Senecio $2950 \times 9$, S. nemorensis, $2 \mathrm{n}$ $=40 ; 10$, S. pseudo-arnica, $2 \mathrm{n}=40$. Arrows point to a pair of the chromosomes with subterminal constrictions.

$50 ， 60 ， 80 ， 90)$ とその段陟的な染芯低の減数によ る異数的誘導による系列群 $(\mathrm{n}=18,24,36,44,46$, 48) の存在が核学的に指摘できる.

この基本数のほかに形態的にも Senecio 属は中部 狭窄型またはこれに近い染色保が絶対的に優占した 刘称的核型であり，核型䅜造は単純であり，個々の 染色体はほとんどそろった大きさをるら，かつ基本 数はキク亚科中最少の $\mathrm{b}=5(2 \mathrm{n}=10)$ を有するな ぞの核学的特性から系統的にかなり原始的な核型で あることを恋めることができよう。

Small10) がかって Senecio 属はキク科中最も原 始的であるといい，他科はこれより派生したと述べ たが，核型的にもややこれに近いことがい壳るので はないだろうか。

次に隣接属の Ligularia 属の L. angusta につ いて考察を進める。 
今回取り报ったL.angusta は Cyathocephala faurèii としてヤマタバコ属に特設されていたもの であるが，やがて Ligularia angusta として現代 の分類所属になり，ヤマタバュ節 Cyathocephalum となったものである4)。これらの分類学的の位置の 変更は特そらく外部形態的根拠に基づいたものであ ろうが，核型的にはどうであろうか。

もともと Ligularia 属には $2 \mathrm{n}=60$ が多いが本種 は $2 \mathrm{n}=58$ である。これは $\mathrm{n}=30$ より減数的に誘 導されたものであろう。核型は非刘称核型であり， Ligularia 属の種と区別すべき核学的特異性はみい だせない、しかし，簃密に観察すれば他の Ligularia 属の種と比較して中部狭窄型䦽よびこれに近い 染色体が多く存在し，核型は Ligularia 属中では 比較的不刘称の度合は小さいものである。

したがって核型的にも Ligularia 属の核型的特 性を共有すると同時に，なた同虽の他種に対し，や


Figs. 11-12. Photomicrographs of the somatic chromosomes of Ligularia, $200 \times .11$, L. angusta, $2 \mathrm{n}=58 ; 12$, L. hodgsonii, $2 \mathrm{n}=$ 58. Arrows point to a pair of the chromosomes with subterminal constrictions.
や区別されるべき核型であることから Cyathocephalum 節として特設することも一応考㝋られる.

これに対し，L. fischerii 特よび L. hodgsonii はいずれも，全般的に前述の L. angustaより高い 非対称核型をもち，さらに高い進化を示しているこ とが認められる。これらは前報告1)の L. dentata, L. stenocephala などと同様な Ligularia 型の核 型をもっている(第 2 表).

前述のように Ligularia 属の大部分の種はいず れも $2 \mathrm{n}=60$ であるが，ほかに若干の $2 \mathrm{n}=58$ の種 が浔められる。 したがって本属の基本数は Senecio 属と同じく 10 (あるいは 5) と考㝋られる. Senecio 属に物いては低次から高次へと段階的の倍数体がみ られるが, Ligularia属に赫いてはいずれも高次の 倍数体 (6n ま先は 12n) あるいはその異数体のみ で低倍数体招よび中間的の倍数体をまったく欠いて いる、和そらく低二倍体から飛躍的に高倍数体が形 成されたとは考えられない，これは最終的にできた 高倍数体物よびこれより誘導された異数体のみが現 在残存して，特殊な環境条件の交鍇する深山，亚高 山，高山，北地，海浜などに適応し分布するに至っ たと考它るのが自然ではないかと和子われる。

Ligularia 属は高倍数体からのみなり, 染色体数 が多数を占めるにかかわらず，その大きさはすべて 大型で太くて長いのが特徵である。これは Stebbins の説11)とは相反する核学的事実である。

以上染色体数特よび核型よりみて Senecio, $L i$ gulariaの両属は系統的に密接な関係をるつことが 示されているが，かなり異なった進化の方向を経て 現在にいたったことを物語っていると考㝋られる。

終わりに終始ご想篤なご指導を赐っている東京都 立大学教授小野記彦博士に蚿心から御礼を申乙上げ る. また材料植物の採集その他に協力を願った北海: 道大学農学部付虏植物圆華園康次氏特よび神奈川県 立真鶴公園蔵品勇夫氏, 当研究室中村卓造副手, 上 島忍君に感觓の微意を呈する。

\section{文献}

1) Arano, H., Bot. Mag. Tokyo 75: 401 (1962)

2) Matsuura, H., and Suto, T., J. Fac. Sci. Hokkaido Univ. 5: 121 (1935). 3) Arano, H., La Chromosomo 53-54: 1794 (1962). 4) Kitamura, S., Mem. Coll. Sci. Kyoto Imp. Univ. (B) 3: 158 (1942). 5) Kitamura, S., Mem. 
Coll. Sci. Kyoto Imp. Univ. (B) 3: 60 (1957). 6) Ornduff, R., and Peter, H., Amer. Jour. Bot. 50: 131 (1963). 7) Afzelius, K., Acta. Horti. Bergiani. 8: 123, 15: 65 (1949). 8) Darlington, C. D., and Wylie, A.P., Chromosome Atlas of Flowering Plants, 262 (George Allen and United Ltd., London, 1956). 9) Beaman J. H., De Jong, D.C.D., and Stoutamire, W. P., Amer. Jour. Bot. 49: 41 (1962). 10) Small, J., New Phytol. 18: 201 (1919). 11) Stebbins, G. L., Variation and Evolution in Plants, 401 (Columbia Univ. Press, New-York, 1950).

\section{Summary}

1) The observations of the chromosome number and the karyotype were carried out on five species of the genus Senecio and Ligularia.

2) The chromosome numbers of S. pseudo-arnica, L. angusta and L. hodgsonii are here reported for the first time.

3) The chromosome numbers of the most species of genus Ligularia appear to be hexaploids of a basic number of ten, and diploid number fifty eight with a basic number of twenty nine which may be derived from thirty, is found in L. angusta and L. hodgsonii.

4) A karyological similarity can be found in S. nemorensis and S. cannabifolius. These two species have rather symmetrical karyotypes, suggesting to be phylogenetically primititve.

5) In spite of the similarity in the external morphology between S. pseudo-arnica and $S$. pierotii, these species have respectively a characteristic karyotype.

6) On the basis of the karyotypical data obtained, the relationship between Senecio and Ligularia was discussed. 